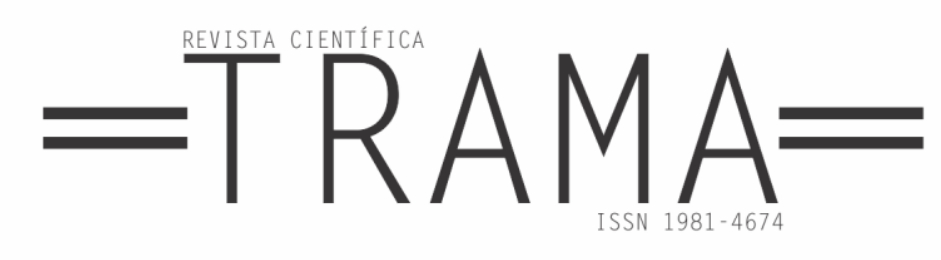

\title{
DA AMIZADE OU A LITERATURA COMO ÉTICA
}

\section{Helano Jader Ribeiro ${ }^{1}$}

RESUMO: Este artigo é a tradução de um pensamento que se dirá aberto. Ou seja, é uma conversa com a autoficção do escritor Thomas Bernhard $\mathrm{O}$ sobrinho de Wittgenstein e seus gestos performáticos que operam na e pela amizade como um conceito que, sobretudo, revela-se através de um discurso politicamente ético e eticamente político. Ao propormos essa autoficção como performance, estamos retirando a representação como presença para em seu lugar enchermos de exageros e encenações performáticas as apresentações neste baile de máscaras e mentiras verdadeiras. Não, aqui se trata de leveza, não de autor[idade], mas sim de um ator chamado Thomas Bernhard. Mas não só. A representação mostra-se aqui em crise porque ficou clara, também, a impossibilidade de representação política.

PALAVRAS-CHAVE: autoficção; amizade; ética; representação.

ABSTRACT: This article is the translation of a thought that will be said open. That is to say, it is a conversation with the autofiction of the writer Thomas Bernhard Wittgenstein's Nephew and his performative gestures that operate in and by the friendship like a concept that, above all, reveals itself through a politically ethical and ethically political discourse. When we propose this autofiction as performance we are withdrawing the representation as presence so instead we fill up with exaggerations and performance scenarios the presentations in this ball of masks and true lies. No, this is lightness, not an author[ity], but an actor named Thomas Bernhard. But not only. The representation is here in crisis because it was also clear the impossibility of political representation.

KEYWORDS: autofiction; friendship; ethics; representation.

Recebido em 15-12-2016

Aceito em 18-03-2017

\footnotetext{
${ }^{1}$ Docente do curso de graduação e pós-graduação em Letras da Universidade Federal de Pelotas (UFPEL). Doutorado em Teoria Literária pela Universidade Federal de Santa Catarina (UFSC).
} 


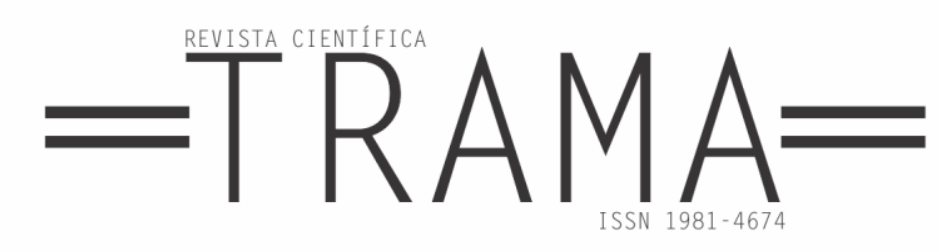

O sobrinho de Wittgenstein: uma amizade ${ }^{2}$ é a história da amizade entre um narrador não nomeado [suposto Thomas Bernhard] e Paul Wittgenstein. Logo na primeira página, há uma indicação de que se trata do próprio Thomas Bernhard como narrador: "Em 1967, no pavilhão Hermann da Baumgartnerhöhe, uma das infatigáveis irmãs que ali trabalhavam como enfermeiras pousou sobre minha cama minha Perturbação [grifo meu], que acabara de ser publicada [...]" (BERNHARD, 1992, p. 7) Perturbação é uma obra escrita por Bernhard e publicada no ano de 1967, mas essa informação é apenas um indício, nada mais.

O narrador é um paciente do pavilhão Hermann para doentes pulmonares. No mesmo complexo hospitalar se encontra Paul Wittgenstein, o sobrinho do filósofo Wittgenstein, no Pavilhão Ludwig para doentes mentais. Este livro de difícil classificação surge como uma obra permeada de elementos memoriais e que carrega sem pudores nomes próprios como o de Thomas Bernhard e Paul Wittgenstein, assim como outros. A repetição de palavras, frases, através do monólogo quase monomaníaco do narrador, chama a atenção para esses mesmos nomes próprios e faz com que a credibilidade em uma suposta verossimilhança seja posta em dúvida:

[...] assim como Paul, é preciso dizer, mais uma vez eu abusara da minha existência, me superestimara e portanto usara e abusara de mim muito além de todas as minhas possibilidades, usara e abusara de tudo além do possível, com essa mesma falta doentia de cuidados comigo e com quem quer que seja, que um belo dia destruiu Paul e que, assim como Paul, me destruirá também um dia desses, pois assim como Paul foi morto por suas ilusões doentias sobre si mesmo e sobre o mundo, eu também, mais cedo ou mais tarde, serei morto por minhas ilusões doentias sobre mim mesmo e sobre o mundo [grifos meus] (BERNHARD, 1992, p. 26-27).

\footnotetext{
${ }^{2}$ O sobrinho de Wittgenstein foi publicado em 1982, três anos depois da morte de Paul Wittgenstein [1907-
} 1979]. 


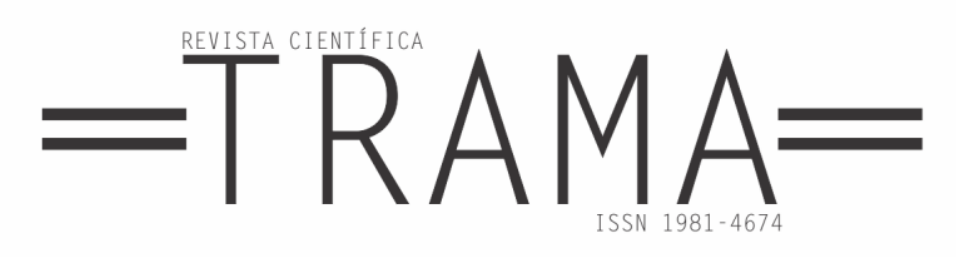

Marjorie Perloff, analisando as obras de Thomas Bernhard e Ingeborg Bachmann, aponta para a problematização do nome próprio relacionado à repetição e da questão nominal nos dois autores:

Para os dois autores, a repetição parece estar intimamente ligada à questão da função nominal. Especialmente a do nome próprio, como Wittgenstein examina nas Philosophical Investigations. Para Bernhard, como veremos, os nomes próprios se desconstroem pela pressão do excesso de repetição [grifo meu] (PERLOFF, 2008, p. 186)

Talvez não se trate de desconstrução, mas Perloff se refere a um apagamento, aniquilamento dos nomes próprios devido ao excesso de repetições. O que quer dizer que a repetição estilística também é responsável pelo apagamento de uma origem absoluta cercada pelo poder de um nome próprio. Bernhard articula, desta forma, a possibilidade da disseminação de sentidos libertos de um nome [uma marca], pondo em cheque a verificação do nome próprio, daquele que assina [torna-o invisível, não-capturável]. É uma tentativa de minar as certezas do eu-suposto-saber cartesiano, e a criação de um espaço incerto em que se possa fazer a operação das resistências, ou como diria Lacan: “[...] a dúvida é agora signo da resistência”" (LACAN, 2008, p. 42).

A respeito desta obra, é difícil sua classificação nos diversos [sub] gêneros existentes em torno dos estudos da escrita de si, como, por exemplo, o romance autobiográfico. Não podemos chamá-la de romance autobiográfico, porque lhe fogem as características com um nome Bernhard que se disfarce com outro nome dentro da narrativa: "O romance autobiográfico se inscreve na categoria do possível, do verossimilmente natural, ele suscita dúvidas sobre sua verificabilidade mas não sobre sua verossimilhança" (KLINGER, 2006, p. 41-42). Talvez autoficção seja o mais acertado. Segundo Diana Klinger: 


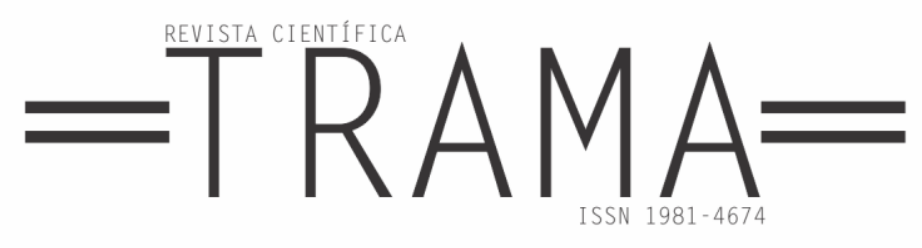

Concebemos a auto-ficção como um discurso que não está relacionado com um referente extra-textual (como no caso da autobiografia), mas também não está completamente desligado dele. A auto-ficção participa da criação do mito do escritor, uma figura que se situa no interstício entre a "mentira" e a "confissão". A noção do relato como criação da subjetividade, a partir de uma manifesta ambivalência a respeito de uma verdade prévia ao texto, permite pensar, como veremos a seguir, a auto-ficção como uma performance do autor (KLINGER, 2006, p. 55).

$\mathrm{Na}$ autoficção, o autor ficcionaliza, mas joga seu nome próprio descaradamente no texto, não precisando se esconder através de outros nomes. Essa seria a crítica apresentada acima em relação ao romance autobiográfico:

A verdade é que contra o pudor do romance autobiográfico pelos nomes próprios e de referências fora do texto, a autoficção tende para o outro extremo e, sem qualquer consideração para as pessoas envolvidas, oferece-os em profusão, tornando-se assim a denúncia da má consciência do romance autobiográfico. ${ }^{3}$

Nos anos que circundam o polêmico texto de Lejeune $\mathbf{O}$ pacto autobiográfico, Serge Doubrovsky publica, em 1977, sua obra de nome Fils. Nela surge seu nome como autor, narrador e personagem, o que poderia ser traduzido, pela teoria de Lejeune, como uma autobiografia. No entanto, esse mesmo texto é apontado pelo próprio Doubrovsky como um livro de cunho ficcional que olha ceticamente para a escritura de si fundada na exatidão de dados verdadeiros do autor. Sua preocupação é de mostrar a falibilidade de uma autobiografia que se legitima pela apresentação fiel da memória [da autoridade de um nome próprio] daquele que se propõe à escritura de sua bios. Ele a chama de autoficção. Em entrevista concedida à Isabelle Grell intitulada C'est fini, Doubrovsky explica a apropriação e popularização do termo:

\footnotetext{
${ }^{3}$ Lo cierto es que contra el pudor de la novela autobiográfica por los nombres propios y referenciales hacia el afuera de texto, la autoficción tiende al otro extremo y, sin ninguna consideración por los implicados, los ofrece con profusión, tornándose así como la denuncia de la mala conciencia de la novela autobiográfica. (AMÍCOLA, 2009, p. 188)
} 


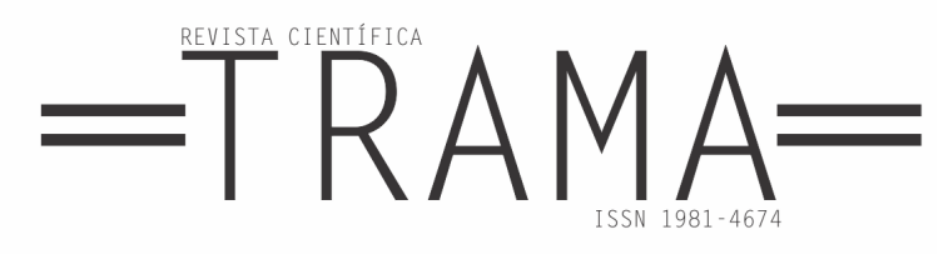

O termo 'autoficção' tem tido um sucesso surpreendente. Quaisquer que sejam as críticas que ele possa ter recebido, e certamente houve abusos e erros graves, esse termo, concebido para o meu uso pessoal, tornou-se corrente não só na França, onde ele entrou para os dicionários Laurousse e Robert, mas, pelo que sei, ele também é empregado frequentemente em inglês, alemão, espanhol, português, italiano e até mesmo polonês (DOUBROVSKY, 2011, p. 23).

Silviano Santiago segue a mesma linha de Doubrovsky ao apresentar seu livro de contos História mal contadas como um trabalho autoficcional. Para ele o conceito de autoficção lhe permitia um deslize pela memória e um descompromisso com a verdade, valendo-se, dessa forma mais de elementos poéticos que miméticos. Silviano Santiago explica sua concepção de autoficção em entrevista concedida à Anna Faedrich Martins:

O falso mentiroso, a que você se refere nas perguntas, pode ser enquadrado dentro do movimento Oulipo. A ideia de autoficção encontra o seu potencial numa escrita Oulipo, ou seja, uma que exige que se escreva um texto ficcional sem se valer de adversativas (MARTINS, 2014, p. 244).

Desta forma, $O$ sobrinho de Wittgenstein poderia se aproximar da definição de autoficção, se imaginarmos Bernhard [esse falso mentiroso] como um ator e seus gestos performáticos. A encenação se arrisca perigosamente dentro da própria escritura e aponta para uma crise maior: a representação.

Derrida em sua crítica ao logos imperativo e à debilidade da phoné encontra um fio condutor para a desconstrução dos binômios da cultura ocidental e do que ele chama de metafísica da presença ${ }^{4}$. Ora, ao mostrar a falência da relação entre significante e significado em Saussure, ele está

\footnotetext{
${ }^{4}$ Deste modo, o logos, o signo é sempre signo de, ou seja, ele representa o objeto em sua ausência, ocupa seu lugar, e só é compreendido no tangente à primazia de que ele é desta mesma falta. Daí se conclui que o signo não significa, pois não há signo nem objeto significado, nesta fissura Derrida encontra espaço para sua abertura.
} 


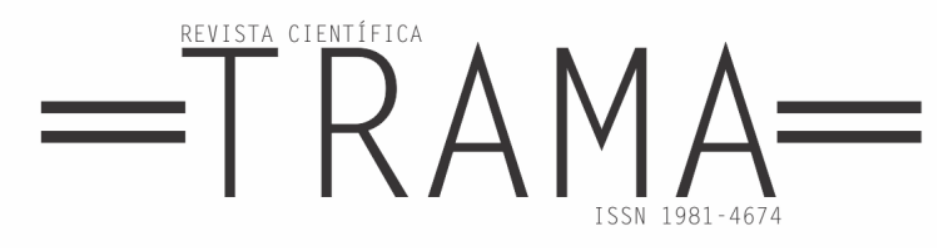

apontando para o signo linguístico e sua incapacidade de representação. Mas notem: este movimento de derrubada da phoné $e^{5}$ se volta não somente para a construção de um pensamento gauche que nega as dicotomias, mas ele é, sobretudo, político. É um falar que engendra, também, a impossibilidade da representação política. Na cultura ocidental toda a idéia de representação gira em função de um ente-sujeito e sua relação representacional com um objeto, tornando este mesmo sujeito dependente do objeto. Entretanto:

Quando o homem determina tudo que existe como representável, ele mesmo se põe em cena, no círculo do representável, colocando-se a si mesmo como a cena da representação, cena na qual o ente deve se re-apresentar, ou seja apresentar novamente (KLINGER, 2012, p. 44).

Assim, podemos falar de uma autoficção bernhardiana que circula dentro da crítica à arte de representação, visto que o narrador, ele mesmo, delineia o tema em suas conversas com o personagem Paul Wittgenstein:

A maior parte das anotações que fiz sobre Paul e sobre mim tratam de música e criminalidade. Do Pavilhão Hermann e do Pavilhão Ludwig, da tensão entre os dois, do Wilhelminenberg, nossa "montanha fatídica", e dos médicos e dos pacientes quem em mil novecentos e sessenta e sete povoavam aquela colina onde nossos destinos se decidiam. Mas sobre política também [grifo meu] [...] ele fustigava o governo corrompido e o Parlamento megalomaníaco, assim como a verdade que fazia os artistas perderem a cabeça, principalmente os artistas dito "reprodutivos". Ele questionava o governo e o Parlamento e o povo inteiro, e a arte criativa assim como a arte dita imitativa [grifo meu] (BERNHARD, 1992, p. 122-123).

Segundo o destaque acima, a própria escritura está apontando para a problemática de se falar em uma arte de imitação, mimética, representativa. Este é um ponto chave de uma escrita de si, autoficção que olha para si mesma. A convicção e aposta na impossibilidade de representação diz

\footnotetext{
${ }^{5}$ A manobra desconstrutiva desmascara através da redução fonética da linguagem a redução da metafísica como o palco do pensamento da cultura ocidental. Gramatologia liberta, dessa forma, o pensamento de sua clausura, fechamento, ao mesmo tempo em que anuncia o advento da escritura.
} 


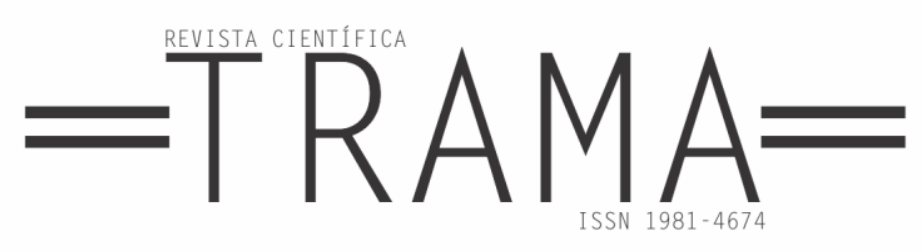

respeito não somente à escrita de si, ela responde ao questionamento do sujeito e sua incapacidade de representação política em nossa democracia, porque essa autoficção é uma resposta política que se esquiva do Estado através de atuação poética, através de máscaras, repetições e exageros: apresentação e não representação.

Ainda em $O$ sobrinho de Wittgenstein, o narrador não expõe um personagem chamado Thomas Bernhard, mas ele joga com o nome de um escritor Bernhard que surge sorrateiramente na narração: "No dia seguinte os jornais austríacos falavam daquele Bernhard que cospe no prato que come, e que ofendera o ministro, quando, na realidade fora o ministro PifflPerčevič que ofendera o escritor Bernhard [grifo meu]" (BERNHARD, 1992, p. 90).

O nome Bernhard aparece como um sopro, gesto, depois de várias páginas de uma narração sem compromisso com um nome. O que se vê é uma aproximação quase teatral de fingimento e atuação. Nesse trecho podemos ler os movimentos performáticos que cruzam a obra, visto que o nome apresentado realiza e concretiza descaradamente essa radicalidade da atuação. Mas por que performance?

A arte da performance supõe uma exposição radical de si mesmo [grifo meu], sujeito enunciador assim como do local da enunciação, a exibição dos rituais íntimos, a encenação de situações autobiográficas, a representação das identidades como um trabalho de constante restauração sempre inacabado (Ravetti, 2002, p. 47). Na arte da performance, o paradoxo do teatro persiste, mas ao contrário deste, o performer está [sic] mais presente como pessoa e menos como personagem. Da mesma forma que na performance, na autoficção convivem o autor (o ator) e o personagem, de tal forma que não se procura aumentar a verossimilhança, pois ela, como vimos, aumentaria paradoxalmente o caráter ficcional. (KLINGER, 2012, p. 51)

$\mathrm{O}$ próprio narrador em $O$ sobrinho de Wittgenstein mostra seu ceticismo em relação ao discurso da verdade, ao usar a amizade com Paul 


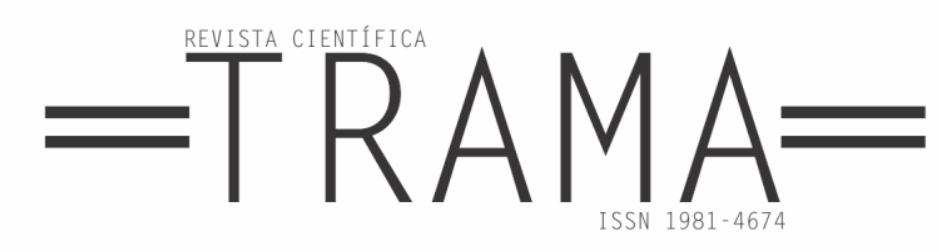

como tema de seu relato [talvez uma desculpa para a tessitura de sua crítica], ele prepara o leitor para lhe mostrar a tênue linha entre verdade e aparência, como se bem vê no trecho a seguir:

Mas, naturalmente, nada é mais difícil do que a verdadeira amizade, a verdadeira prestabilidade, a verdadeira dedicação e a fronteira entre o verdadeiro e o aparente é, também nesse aspecto, difícil de estabelecer. Pensamos durante muito tempo que se trata de algo verdadeiro enquanto se trata de algo aparente para o que ficamos cegos durante muito tempo [grifos meus] (BERNHARD, 1992, p. 61).

Ora, na autoficção não se trata de verdade, mas da fala de um autor/ator que, assim como o narrador acima alerta, não deixa de nos avisar que ele mesmo é pouco confiável. No lugar de algo verdadeiro entra o que Diana Klinger chama de mitos do escritor:

A autoficção é uma máquina produtora de mitos do escritor, que funciona tanto nas passagens em que se relatam vivências do narrador quanto naqueles momentos da narrativa em que o autor introduz no relato uma referência própria à escrita [...]. A autoficção participa da criação do mito do escritor, uma figura que se situa no interstício entre a "mentira" e a "confissão" [grifo meu] (KLINGER, 2012, p. 46).

O delineamento de um conceito da autoficção desmaterializa, desta forma, pelo des-fazer de categorias de verossimilhança, os limites entre a suposta verdade de si e a ficção, ou seja, impõe uma análise outra à proposta de Philippe Lejeune e sua teoria de fechamento baseada no pacto autobiográfico. A autoficção é, pois, performance, gesto, escuta. Para o narrador em $O$ sobrinho de Wittgenstein fica claro que sua história contingente é uma constelação de fragmentos, ou melhor, esse sujeito é não pleno, revela-se difuso em sua contingência, ou, melhor ainda, ele é uma construção aberta, quase inorgânica e fluída, que irá sempre variar de acordo com esses mesmos gestos e movimentos dançantes de esquiva. 


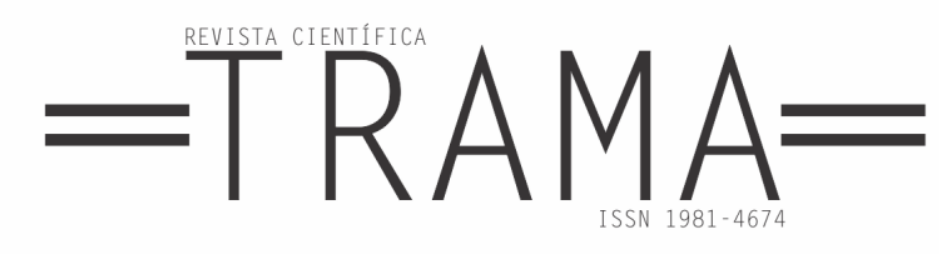

A loucura de Paul Wittgenstein se revela, então, como uma ameaça onipresente em $O$ sobrinho de Wittgenstein, ela é quase um terceiro elemento que se personifica. $\mathrm{O}$ que se nota é uma explanação do narrador que muitas vezes parece, também, beirar à loucura: "Mas Paul não se tornou mais louco do que eu próprio sou, pois sou pelo menos tão louco quanto Paul era, só que, além da minha loucura, fiquei também doente dos pulmões" (BERNHARD, 1992, p. 29).

A instalação do hospital, localizada na periferia de Viena é parte integrante de um complexo hospitalar, uma espécie de não-lugar localizável na cartografia da cidade, onde o conceito epistemológico da clínica se impõe diante das subjetividades dos doentes. Este lugar outro, ainda, marca um território estriado, não rizomático, não desejante, ponto de inflexão em que o discurso do esclarecimento cava seu poder. O complexo de Steinhof é essa espacialidade heterotópica no sentido empregado por Foucault de abrigo dessas singularidades aprisionadas:

Quanto às heterotopias propriamente ditas, como se poderia descrevê-las, que sentido elas têm? Seria possível supor, não digo uma ciência - porque é uma palavra muito depreciada atualmente - mas uma espécie de descrição sistemática que teria por objeto, em uma dada sociedade, o estudo, a análise, a descrição, a "leitura", como se gosta de dizer hoje em dia, desses espaços diferentes, desses outros lugares, uma espécie de contestação simultaneamente mítica e real do espaço em que vivemos; essa descrição poderia se chamar heterotopologia (FOUCAULT, 2001, p. 415-416).

Steinhof é, assim, a representação moderna do conhecimento científico humano, ou uma máquina de cuidado disciplinar do outro. Bernhard arma, desta forma, metodologicamente, uma genealogia desses mesmos lugares precedidos por análise de sua origem [no sentido de arché], se trata também de uma investigação arqueológica em que corpos e história não podem ser diferenciados, visto que a história é, também, a narrativa do corpo [bíos], seu enclausuramento [fechamento] e controle. Assim, todo este 


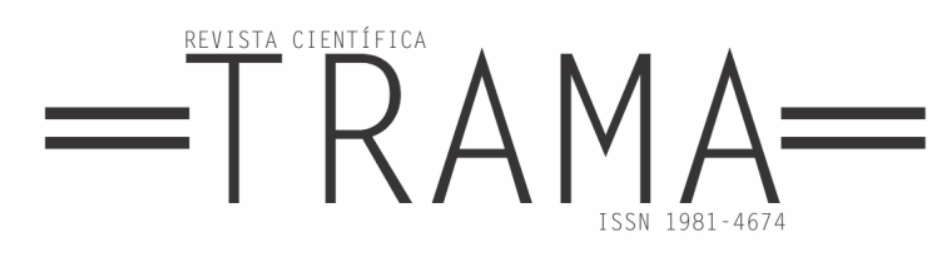

complexo de Steinhof pode ser lido como um dispositivo, porque ele é apropriação de todo corpo desejante de desejo, de toda subjetividade:

O homem procura fazer girar em vão os comportamentos animais que se separaram dele e gozar assim do Aberto como tal, do ente enquanto ente. Na raiz de todo dispositivo está, deste modo, um desejo demasiadamente humano de felicidade, e a captura e a subjetivação deste desejo, numa esfera separada, constituem a potência específico do dispositivo (AGAMBEN, 2009, p. 43-44).

O sobrinho de Wittgenstein, ainda, se apresenta como mais um dos numerosos textos de Bernhard em que o tema da amizade se revela carregado de tristeza e melancolia, através de uma escritura desesperançada, mas política. Há, aqui, uma aproximação clara entre amizade, sobrevivência e morte, temas caros a Thomas Bernhard, como bem se vê através da epígrafe de abertura: "Duzentos amigos [grifo meu] assistirão ao meu enterro e você deverá fazer um discurso à beira do meu túmulo" (BERNHARD, 1992, p. 5). A frase aparece novamente no último parágrafo, o narrador revela, finalmente, ser este um pedido do amigo Paul. No entanto, apenas pouquíssimas pessoas compareceram ao funeral e o próprio narrador esteve ausente na cerimônia.

O narrador aponta para a morte do amigo, para que, somente assim, esse amigo morto possa viver através da lembrança daquele que sobreviveu. O discurso não feito é, desta forma, recuperado pela escritura, algo semelhante ao que Jacques Derrida fez em relação ao amigo Lévinas. Essa memória sobrevivente é, ao mesmo tempo, a condição que faz a amizade algo possível e o tempo da sobrevivência da mesma amizade. Desse luto em torno da ausência do amigo, Derrida constrói um relato como uma sobrevivência possível após a própria morte:

Eu assinalaria hoje que nossa tristeza infinita deveria se guardar de tudo aquilo que, no luto se dirigiria para o nada, quer dizer aquilo que une ainda, mesmo que 


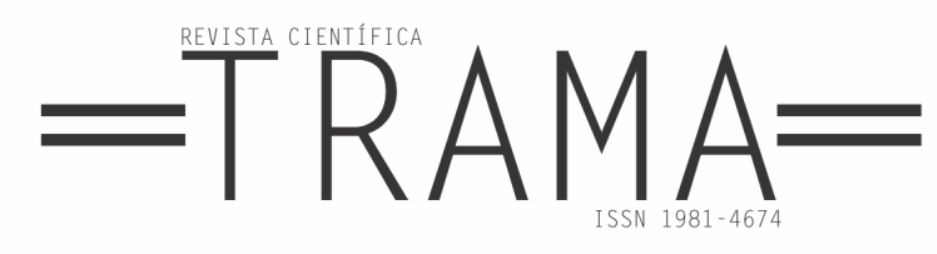

potencialmente, a culpabilidade ao assassinato. Efetivamente, Lévinas fala da culpabilidade do sobrevivente. Porém, é uma culpabilidade sem falta e sem dívida, na verdade, uma responsabilidade confiada, e confiada num momento de emoção sem equivalente, no momento em que a morte permanece a exceção absoluta (DERRIDA, 2004, p. 22).

O telos dessa amizade sobrevivente em $O$ sobrinho de Wittgenstein é em si contraditório: de um lado tem-se a alegria da tão desejada sobrevivência, de outro a culpa pela mesma sobrevivência, ou algo semelhante ao que Primo Levi e outros sobreviventes dos campos de concentração relatavam após terem conseguido a sonhada liberdade e sobrevivência, se pensarmos que muitos outros morreram.

Enquanto um eu-narrador inominado descreve o espaço da clínica para doentes do pulmão, surge paulatinamente o personagem Paul Wittgenstein, que é levado para a clínica de doentes mentais. $\mathrm{O}$ encontro entre os dois se dá num ponto de intermédio entre as duas clínicas, em um banco. Num primeiro momento do livro, amizade e sobrevivência são os fios condutores da narrativa. Posteriormente, na elaboração narrativa em um segundo momento, o narrador desloca-se cuidadosamente pela derrocada física do amigo Paul, distanciando-se da espacialização da clínica [posição política] para ir à direção da exploração mais subjetiva e emocional de um eu rasgado pela memória. Mostrando-se cada vez mais distante do amigo em seu estágio final de vida, o narrador articula todo um cenário em torno de sua própria existência e sobrevivência [plano ontológico]: "afastei-me do meu amigo, assim como seus outros amigos, porque como eles, eu queria me afastar da morte. Temia o confronto com a morte. Pois tudo, em meu amigo, já estava morto." (BERNHARD, 1992, p. 113) A morte do amigo provoca, assim, um luto sem fim.

O luto, então, vem trabalhado através da pronúncia do nome do outro, do nome próprio. A repetição bernhardiana assinala, até o limite do 


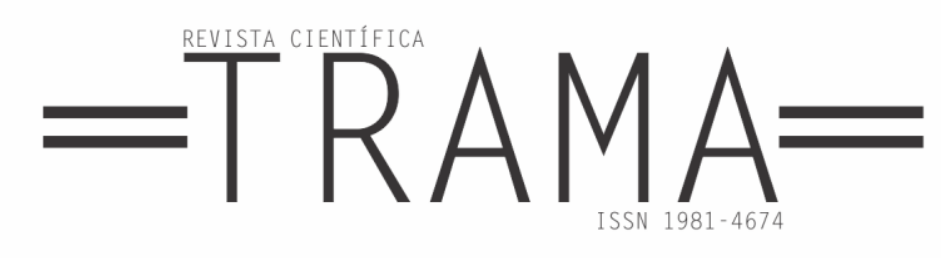

impossível, essa mesma mortalidade. O chamado não é nada menos que a evocação de um ente que se faz ausente, o nome próprio do amigo Paul Wittgenstein somente marcaria essa ausência. A falta de Paul é da ordem do vazio falante:

Paul se tornou louco porque um dia ele se revoltou subitamente contra tudo e que, naturalmente, por causa disso, ele deu o mergulho, assim como eu mergulhei um belo dia porque, como ele, eu me revoltei contra tudo [...] Mas Paul não se tornou mais louco do que eu próprio [...[ Paul era, pelo menos, tão louco quantos as pessoas diziam que Paul era [...] A única diferença entre mim e Paul é que Paul [grifos meus] se deixava dominar inteiramente por sua loucura (BERNHARD, 1992, p. 28-29).

A amizade entre Bernhard e Paul se revela, sobretudo, através de sua simetria espiritual, pela paixão pela música, pelo estranho senso de humor que os unia e um desgosto amargo pela sociedade burguesa de Viena. $O$ sobrinho de Wittgenstein é tanto uma meditação sobre a luta do artista e sua sobrevivência em um mundo torto, incompreensível, quanto uma elegia à amizade.

Giorgio Agamben, em seu texto $\mathbf{O}$ amigo nos diz: "O que é, de fato, a amizade senão uma proximidade tal que dela não é possível fazer nem uma representação [grifo meu] nem um conceito?" (AGAMBEN, 2009, p. 85). A impossibilidade de fechar conceitualmente a amizade ou de fazer dela uma representação como qualidade ou propriedade do sujeito é fundamental em nossa análise sobre $O$ sobrinho de Wittgenstein, livro este que tem como subtítulo uma amizade, visto que essa abertura através do tema da amizade é, sobretudo, política. O contato, a descrição da proximidade daquelas duas existências, realiza-se, com frequência, do plano político ao ontológico.

Em determinado ponto, em que o narrador descreve o recebimento do prêmio Grillparzer de Literatura, a amizade com Paul Wittgenstein surge como cúmplice de ataque ao cenário literário na Áustria: "Ele foi o único, juntamente com meu ser vital, que descobriu todo o sonso disparate dessa 


\section{$=$ TRAMA $=$}

entrega de prêmios e definiu essa grotesca cerimônia como ela merecia: uma perfídia bem austríaca" (BERNHARD, 1992, p. 81). Um pensamento escandaloso como o de Bernhard nos possibilita a denúncia em torno da hipócrita entrega de prêmios literários, de acordo com o crítico Hans Höller:

Na cerimônia de atribuição do Prêmio Grillparzer por ocasião da "Comemoração Grillparzer da Academia" em função do centenário da morte de Grillparzer em janeiro de 1972 , o nome de Bernhard nem sequer figurou no Programa, que, no entanto, privilegiou todos os violinistas de acompanhamento musical. Em Sobrinho de Wittgenstein Bernhard dá sua versão tanto da Cerimônia de premiação do Estado quanto da humilhante festa na Academia das Ciências em Viena. $^{6}$

A amizade entre Paul e o narrador surge, assim, como um comsentimento do outro, ou, melhor ainda, um outro si, outro autos, que se revela através desse mesmo com-sentir. E se esse projeto de comunidade de Thomas Bernhard é pensado, sobretudo, pela partilha existencial do outro cuja política é a da amizade [e uma amizade política], é porque essa divisão do comum, sua comunidade de singularidades, tem, ao mesmo tempo, um caráter político e ontológico, ou como diria Agamben: "a amizade é a condivisão que precede toda divisão, porque aquilo que há para repartir é o próprio de existir [grifo meu], a própria vida. E é essa partilha sem objeto, esse com-sentir originário que constitui a política [grifo meu]" (AGAMBEN, 2009, p. 92). Mas como pensarmos a questão da alteridade, da abertura de si para outro como uma política ontológica? Nesse sentido, a questão da hospitalidade colocada por Derrida, é de suma relevância para delinearmos nosso pensamento.

\footnotetext{
${ }^{6}$ Bei der Verleihung des Grillparzer-Preises anläßlich der «Grillparzer-Gedenkfeier der Akademie» zum hundertsten Todestag Grillparzers im Jänner 1972 figurierte Bernhard nicht einmal auf dem Programm, das gleichwohl jeden Geiger der musikalischen Umrahmung namentlich anführte. In Wittgensteins Neffe gibt Bernhard seine Version sowohl von der Staatspreis-Verleihung als auch von dem für ihn erniedrigenden Festakt in der Akademie der Wissenschaften in Wien (HÖLLER, 1994, p. 12).
} 


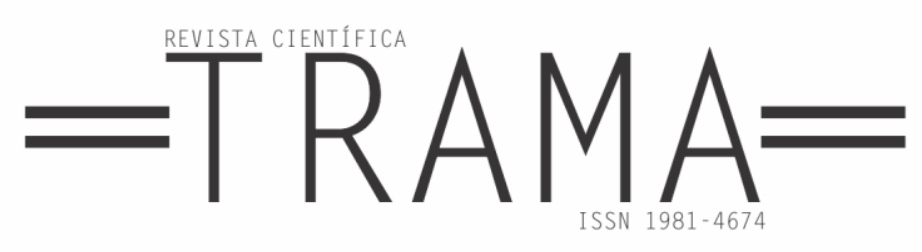

Em língua alemã, a palavra estrangeiro, Ausländer, é composta pela partícula aus que significa de fora e de Länder, que significa terras, países. Este estranho - em alemão traduzido por Fremd -, ou estranho, diferente é aquele que vem de fora, penetra novas terras e provoca naqueles que o recebem sentimentos ora de alegria, ora de apreensão e dúvida. O estrangeiro procura na terra e língua estranhas a hospitalidade de seus hospedeiros.

A hospitalidade, segundo Derrida, é vista como uma reciprocidade de responsabilidade entre o $\mathrm{eu}$ e o outro, enfocando o crescimento das relações provenientes desse encontro e do contato estabelecido entre aquele que a princípio nos parece diferente, estranho por características físicas, culturais, lingüísticas ou até mesmo por ser desconhecido. Circular nesta inscrição do idioma da hospitalidade total, aquela a revelar-se na entrega, é doar-se ao o outro em sua estranheza - Fremdartigkeit -, ou seja, livre de qualquer apreensão pré-concebida. A hospitalidade incondicional consiste em receber o outro antes de lhe colocar qualquer condição, impor-lhe nossa verdade, antes mesmo de lhe perguntar o nome ou qualquer tipo de identificação que lhe revele como sujeito. Daí vem o desconforto causado pela ausência de identidade:

Justamente por estar inscrito num direito, um costume, um ethos e uma Sittlickeit, essa moral objetiva [...] supõe um estatuto social e familiar dos contratantes, a possibilidade de que possam ser chamados pelo nome, de ter um nome, de serem sujeitos de direito, dotados de uma identidade nominável e de um nome próprio. Um nome próprio não é nunca puramente individual [grifo meu]. Se nos detemos um pouco mais sobre esse dado significativo, pode-se notar mais um paradoxo ou uma contradição: esse direito à hospitalidade oferecido a um estrangeiro "em família", representado e protegido por seu nome de família é ao mesmo tempo o que torna a hospitalidade ou a relação de hospitalidade com o estrangeiro, o limite e o proibido. Nessas condições, não se oferece hospitalidade ao que chega anônimo e a qualquer um que não tenha nome próprio, nem patronímico, nem família, nem estatuto social, alguém que logo seria não como estrangeiro, mas como mais um bárbaro [grifo meu] (DERRIDA, 2003, p. 23). 


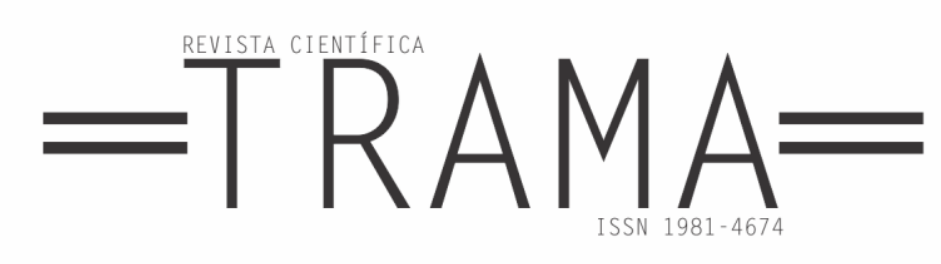

Mas por outro lado, a hospitalidade exige de nós uma doação de nossa singularidade como um gesto de troca, um pacto que existe entre hóspede e hospedeiro. Derrida, a partir de análise de Émile Benveniste, conclui, a respeito da palavra hostis que, em latim, significa não somente hóspede, mas também hostil, inimigo; ele passa a criar, desta forma, o termo hospitalidade. A partir dessa fusão geradora de incongruência, a nova palavra, que amalgama hostilidade e hospitalidade, explicita um conceito que reúne a ambigüidade do movimento daquele que recebe e daquele que chega.

No livro Sob palavra, uma reunião de entrevistas de Derrida, o tema da hospitalidade é levantado em pauta com urgência, uma urgência que é vista por Derrida e sua investigação do pensamento do filósofo Emmanuel Lévinas: a análise da questão da alteridade, ponto central de seu trabalho. Para Lévinas o outro continuará sempre a ser outro e, ainda que pensemos o outro como si-próprio, que imaginemos o outro como mesmo do si-próprio, existirá sempre um resto de alteridade que jamais poderemos alcançar:

\begin{abstract}
A hospitalidade, no que Lévinas faz do termo, não se reduz simplesmente, embora isso também, ao acolhimento do estrangeiro em si próprio, na própria casa, na própria nação, na própria cidade. A partir do momento em que me abro, faço "acolhimento" para retomar o termo de Lévinas, à alteridade do outro, estou já numa disposição hospitaleira. A própria guerra, a rejeição, a xenofobia supõem que me ocupe de outro e que por conseguinte esteja já aberto ao outro. O fecharse não é mais que uma reacção a uma primeira abertura. Deste ponto de vista, a hospitalidade é primeira. Dizer que é primeira significa que antes mesmo de ser eu próprio, e quem sou, ipse, é necessário que a irrupção do outro tenha instaurado essa relação de mim a mim próprio. Por outras palavras, não posso ter relações comigo próprio, com meu "em mim", a não ser na medida em que a irrupção do outro precedeu a minha própria ipseidade. É por isso que, na trajectória de Lévinas que eu tento reconstituir um pouco nesse livrinho, se parte de um pensamento do refém. Sou de certa maneira refém do outro, e esta situação de refém em que sou já convidado do outro, esta situação de refém define a minha própria responsabilidade (DERRIDA, 2004, p. 61-62).
\end{abstract}

De um ponto de vista, o desconhecido se torna conhecido por sua identidade, pelo nome que carrega do pai. Citando Derrida sobre o 


\section{$=$ TRAMA $=$}

estrangeiro: “ele sabe antecipadamente ser posto em questão pela autoridade paterna e razoável do logos, a instância paterna do logos se prepara a desarmá-lo, a tratá-lo como louco [grifo meu]" (DERRIDA, 2003, p. 11). O que interessa, então, a Derrida não é aquele hóspede, estranho, que carrega claramente seu nome, a marca paterna, mas aquele que impõe o que Derrida chamará de hospitalidade absoluta, ou seja, aquele para quem o hospedeiro abrirá a sua casa, sem exigir nada em troca, nem mesmo seu nome, num ato de entrega e confiança absolutas.

Segundo Derrida, a hospitalidade não deve ser vista somente como uma aceitação da diferença, mas como um aprendizado que esse contato oferece. O contato com o outro faz com que o eu exista, o que nos faz entender que o outro é responsável pela sua representatividade, pois pela interação, pode reformular ou não o eu. O outro representa o que o eu ainda não é, o que eu posso vir através de um devir-louco que se perde nesse outro. $\mathrm{O}$ ato da hospitalidade aproxima o eu desinteressado e leva ao outro, através de seu desejo de ser-com, abrindo espaço para o jogo nesse campo imanente de sensações alheias.

Em outro seminário, Derrida dedica-se de forma breve ao tema da hospitalidade, Dire l'événement, est-ce possible?, seminário apresentado em Montreal no ano de 1997 com a presença de Gad Soussana e Alex Noussa. Nele, Derrida expõe que a hospitalidade não consiste somente em receber aquele por quem ansiamos ou nos compraz, mas essencialmente, pelo hóspede inesperado, ou indesejado, aquele que desafia nossa própria subjetividade:

A hospitalidade não consiste simplesmente em receber o que não é capaz de receber. Lévinas diz que qualquer parte em que o sujeito é um hospedeiro (anfitrião) que está hospedando o infinito além de sua capacidade. Acolher além de sua capacidade de acolher: significa que eu devo receber ou que recebo ou eu 


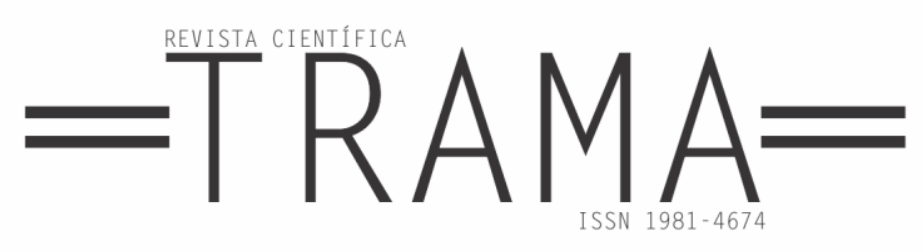

não posso receber, além da vinda do outro que me excede, que parece maior que meu lar. ${ }^{7}$

Em seu seminário com Anne Dufourmantelle, Derrida discute a interferência do Estado em relação à intervenção de controle e apagamento de arquivo virtual, acerca de um determinado material pornográfico existente na internet na Alemanha, mostrando a tênue linha entre o público e o privado, bem como a interferência estatal na esfera do chez-soi: "Essa máquina interdita a hospitalidade, o direito à hospitalidade, que ela própria deveria tornar possível". (DERRIDA, 2003, p.93) O Estado, diz ele, cada vez mais diminuído diante do potente arquivo virtual, procura com todos seus esforços controlar e invadir um espaço, que legalmente não lhe diz respeito.

A condição de estrangeiro em sua própria terra mostra a impropriedade do próprio e a fragilidade da dualidade entre externo e interno. O estranho não se apresenta como essência em oposição ao próprio, mas ambos adquirem suas significações nas decisões e gestos políticos. O estrangeiro em seu próprio território vem a expor que a condição de pertencimento é fundamentalmente arbitrária e móvel, é uma determinação do controle político sobre a vida. Ao ocupar o espaço da não-linguagem e tornar inoperante o poder da linguagem, manifesta que não há uma sem a outra, que não há dentro sem fora, e vice versa e que, portanto, assim como o próprio e o estrangeiro, são forças que não preexistem mas que se fazem em seu enfrentamento. Hostis, o termo latino outrora mais próximo do campo semântico da hospitalidade e da amizade, se aproxima historicamente cada vez mais da hostilidade, justamente porque o encerramento no próprio provoca a rejeição da diferença.

\footnotetext{
${ }^{7}$ L'hospitalité ne consiste pas simplement à recevoir ce qu'on est capable de recevoir. Lévinas dit quelque part que le sujet est un hôte qui doit accueillir l'infini au-delà de sa capacité d'accueil. Accueillir au-delà de sa capacité d'accueil: cela veut dire que je dois recevoir ou que je reçois là ou je ne peux pas recevoir, là ou la venue de l'autre m'excède, paraît plus grande que ma maison (DERRIDA, 2011, p.97).
} 


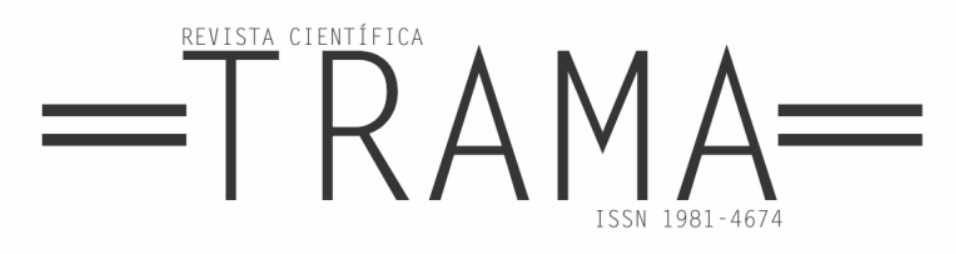

O Sobrinho de Wittgenstein é uma alteridade pura [je est un autre], não se trata apenas do sobrinho de Wittgenstein, mas sim desse narrador à procura de si no outro, na amizade. Bernhard mostra nossa incompletude, e ao mesmo tempo, a construção de nossa subjetividade a partir da experiência com o outro: o amigo ou esse conhecido-estranho [Unheimlich]. Das Unheimliche é um conceito de Freud elaborado através da obra de E.T.A. Hoffmann. Freud mostra aquilo que causa o medo, das Unheimliche, é aquele terror que remonta ao que é desde há muito conhecido e ao qual se está há muito acostumado. Seu contrário heimlich, familiar, conhecido, é a ligação direta com a palavra Heim [casa, lar, aconchego]. Contendo heimlich igualmente o significado de em segredo, velado, o efeito do unheimlich surge, quando o que deveria ficar oculto é desvelado: intimamente estranho:

O inquietante é um desses domínios. Sem dúvida, relaciona-se ao que é terrível, ao que desperta angústia e horror, e também está claro que o termo não é usado sempre nu sentido bem determinado, de modo que geralmente equivale ao angustiante (FREUD, 2010, p. 329).

Este mesmo narrador se revela através da voz do outro estranho [Fremd], mas que é seu amigo [Freund], ou alteridade que suscita uma inquietante familiaridade. O bode expiatório de nome Paul Wittgenstein é constantemente apropriado pelo narrador para falar de si mesmo:

Assim como Paul, durante anos, praticamente se precipitara à morte em sua loucura, eu durante anos, praticamente me precipitara à morte na minha. Assim como o caminho de Paul devia periodicamente dar e se interromper num asilo de alienados, do mesmo modo meu caminho devia periodicamente dar e se interromper num serviço de pneumotisiologia (BERNHARD, 1992, p. 27).

Assim, a autoficção de Thomas Bernhard, essa escritura bárbara, aparece em sua desaparição, revela-se nesse jogo de não identidade, mas que, ao mesmo tempo, opera com uma suposta identidade crítica, implacável e não captável, exatamente através do álibi da fabricação de ficções. Ela exige 


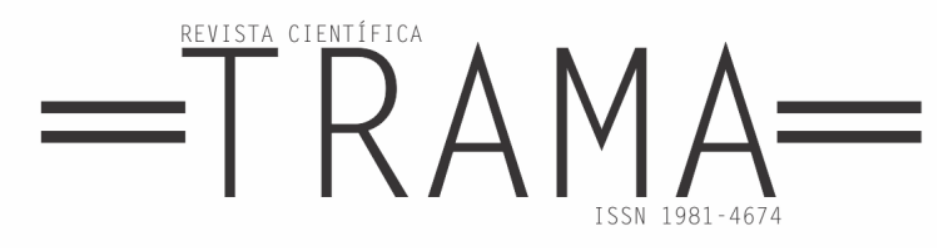

hospitalidade incondicional, visto que é figura que não se deixa encerrar em uma identidade. A autoficção é um traço não batizado à espera de sua ontologização. Astuto e potente, representa uma operação política que só é possível pela elaboração da amizade como força de [fora da] lei ética e inoperante.

\section{REFERÊNCIAS}

AGAMBEN, Giorgio. O que é o contemporâneo?. In: O que é o contemporâneo e outros ensaios. Tradução de Vinícius Nicastro Honesko. Chapecó: Argos, 2009.

AGAMBEN, Giorgio. O amigo. In: O que é o contemporâneo e outros ensaios. Tradução de Vinícius Nicastro Honesko. Chapecó: Argos, 2009.

BERNHARD, Thomas. O sobrinho de Wittgenstein. Uma amizade. Tradução de Ana Maria Scherer. Rio de Janeiro: Rocco, 1992.

DERRIDA, Jacques. Da hospitalidade. Tradução de Antônio Romane. São Paulo: Escuta, 2003.

DERRIDA, Jacques. Sob palavra: instantâneos filosóficos. Tradução de Miguel Serras Pereira. Lisboa: Fim de Século, 2004.

DERRIDA, Jacques. Anne Dufourmantelle convida Jacques Derrida a falar Da Hospitalidade. Tradução de Antonio Romane. São Paulo: Escuta, 2003.

DERRIDA, Jacques. Dire L'événement, est-ce possible?: Séminaire de Montréal, pour Jacques Derrida. Paris l'Harmattan, 2011.

DERRIDA, Jacques. Adeus a Emmanuel Lévinas. Tradução de Fábio Landa. São Paulo: Perspectiva, 2004.

DOUBROVSKY, Serge. C'est fini. Entretien réalisé par Isabelle Grell. In: FOREST, Philippe. La Nouvelle Revue Française. Je \& Moi. Paris: Gallimard, n. 598, octobre 2011.

FOUCAULT, Michel. Outros espaços: heterotopias. In: Ditos e escritos - Vol. III. Tradução de Inês A. D. Barbosa. Rio de Janeiro: Forense Universitária, 2001.

FREUD, Sigmund. O inquietante. In: Obras Completas Vol 14. Tradução de Paulo César de Souza. São Paulo: Companhia da Letras, 2010. 


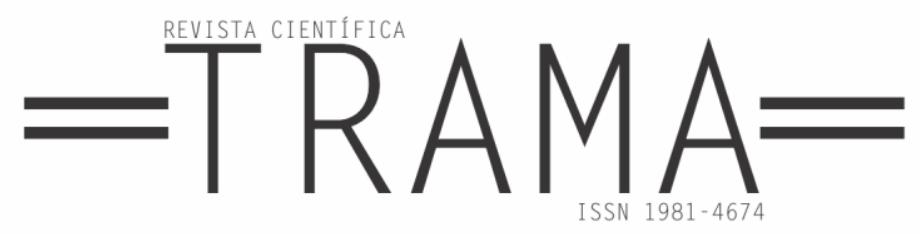

KLINGER, Diana. Escritas de si e escritas do outro: Auto-ficção e etnografia na literatura latino-americana contemporânea. Tese de Doutorado em Letras. Literatura Comparada. Rio de Janeiro: UERJ, 2006.

LACAN, Jacques. O seminário, livro 11, Os quatro conceitos fundamentais da psicanálise. Rio de Janeiro: Jorge Zahar, 2008.

MARTINS, Anna Faedrich. Autoficções: do conceito teórico à prática na literatura brasileira contemporânea. Tese de Doutorado em Letras. Literatura Comparada. Porto Alegre PUC, 2014.

PERLOFF, Marjorie. Jogos-Limite: As Ficções de Wittgenstein por Thomas Bernhard e Ingeborg Bachmann. In: A Escada de Wittgenstein: a Linguagem Poética e o estranhamento do Cotidiano. Tradução de Elisabeth Rocha Leite; Aurora Fornoni Bernardini. São Paulo: Editora da Universidade de São Paulo, 2008. 